\title{
Tecnologias digitais de informação e comunicação (TDIC) e processo de ensino
}

\author{
Antonio Sandro Schuartz \\ Helder Boska de Moraes Sarmento ${ }^{2}$ \\ https://orcid.org/0000-0002-2114-7509 \\ https://orcid.org/0000-0003-3156-3626 \\ ${ }^{1}$ Universidade Federal do Paraná, Curso de Serviço Social, Matinhos, PR, Brasil \\ ${ }^{2}$ Universidade Federal de Santa Catarina, Departamento de Serviço Social, Programa de Pós- Graduação em Serviço Social, Florianópolis, \\ SC, Brasil
}

Tecnologias digitais de informação e comunicação (TDIC) e processo de ensino

Resumo: As Tecnologias Digitais de Informação e Comunicação (TDIC) permitem, hoje, um intenso e crítico diálogo entre educação e tecnologias. Nesse sentido, este artigo apresenta os resultados da pesquisa de doutorado com objetivo de identificar as TDIC utilizadas pelos professores dos cursos de Serviço Social nos processos de ensino e aprendizagem. Da mesma forma, pretendeu-se descobrir os objetivos com que tais recursos estão sendo utilizados na formação dos futuros assistentes sociais, posicionando-os em relação aos níveis de certificação das competências pedagógicas em TDIC. A investigação teve por base um questionário on-line aplicado a um conjunto de professores vinculados a Instituições de Ensino Superior (IES) públicas que oferecem graduação em Serviço Social no estado do Paraná. Os resultados apontam para um uso instrumental das TDIC nos processos de ensino e aprendizagem.

Palavras-chave: Docência. TDIC. Formação Profissional. Serviço Social.

\section{Information and Communication Technology (ICT) and teaching process}

Abstract: The Information and Communication Technology (ICT) allow, nowadays, an intense and critical dialogue between education and technologies. Seen in these terms, this article presents the results of a doctoral research in order to identify the ICT used by teachers of Social Work courses in the teaching and learning processes. In the same manner, it was intended to discover the objectives with which these resources are being used in the training of future social workers, positioning them with regard to the certification levels of teaching skills in ICT. The research was based on an online questionnaire applied to a group of teachers bounded to public Institutions of Higher Education that offer degrees in Social Work in the state of Paraná. The results indicate to an instrumental use of ICT in the teaching and learning processes.

Keywords: Teaching. ICT. Professional Training. Social Work

Recebido em 28.02.2020. Aprovado em 04.04.2020. Revisado em 12.06.2020.

(C) O(s) Autor(es). 2020 Acesso Aberto Esta obra está licenciada sob os termos da Licença Creative Commons Atribuição-NãoComercial 4.0 Internacional (https://creativecommons.org/licenses/by-nc/4.0/deed.pt_BR), que permite copiar, distribuir e reproduzir em qualquer meio, bem como adaptar, transformar e criar a partir deste material, desde que para fins não comerciais e que você forneça o devido crédito aos autores e a fonte, insira um link para a Licença Creative Commons e indique se mudanças foram feitas. 


\section{Introdução}

As Tecnologias de Informação e Comunicação (TDIC) permitem, hoje, ministrar uma aula de forma muito mais dinâmica, interativa e colaborativa do que no passado. Para tanto, exige-se repensar as práticas pedagógicas existentes, o que se mostra um desafio aos docentes na contemporaneidade: agregar às práticas de ensino e aprendizagem recursos disponíveis em TDIC. Trata-se de uma demanda já estabelecida, à medida em que se assiste aos avanços tecnológicos em relação à informação e comunicação, bem como ao aumento do uso dessas ferramentas pelas camadas mais jovens, as quais têm tomado assento nas salas de aula de Serviço Social.

Ao perceber as transformações que as novas tecnologias trazem à educação, não há como deixar de questionar o papel do professor nesse universo digital. Entende-se, porém, que ele não perde o seu papel central, mas que são acrescidas novas possibilidades ao ensino. Essas possibilidades são trazidas pelas tecnologias digitais, algumas até então impensadas, por exemplo, utilizarmos o Google Earth e passearmos pelo território administrado por um Centro de Referência em Assistência Social (CRAS).

Considerando esse cenário, este artigo apresenta os resultados do estudo descritivo que buscou identificar as TDIC que têm sido utilizadas pelos professores dos cursos de Serviço Social nos processos de ensino e aprendizagem. Da mesma forma, pretendeu-se descobrir os objetivos em que tais recursos estão sendo utilizados na formação dos futuros assistentes sociais.

Para tanto, este artigo está dividido em três seções. A primeira apresenta uma revisão de literatura em que se busca averiguar como esta tem abordado a questão das TDIC e o que vem sendo exigido dos docentes frente a essa nova realidade. Destaca-se, na mesma seção, as competências esperadas por parte dos professores em relação a tais tecnologias.

A segunda seção relata o percurso metodológico trilhado pela pesquisa, descreve o seu universo e os sujeitos que dela participaram. Aponta, ainda, o modo como foi realizada a coleta dos dados, seu agrupamento e análise, permitindo encontrar subsídios para as reflexões trazidas pelo estudo.

$\mathrm{Na}$ terceira seção são apresentadas reflexões finais que emergiram dos estudos realizados que fundamentaram este artigo, como dos dados trazidos pela pesquisa on-line.

\section{Tecnologia digital de informação e comunicação (TDIC): desafios postos à docência}

Cantini et al. (2006) apontam reflexões sobre o impacto que as inovações tecnológicas trazem à vida social, profissional e acadêmica, especialmente no que tange à formação de professores frente às TDIC. Os autores entendem que os professores se encontram passivos frente a tais mudanças e à incorporação de artefatos tecnológicos em sala de aula. Imputam tal comportamento à ausência de um fomento que os instigue a tal apropriação durante a sua formação, e à falta de um suporte técnico e pedagógico nos espaços educacionais. Mas há, também, outro fator nesta questão: o próprio interesse por parte do professor.

O professor, como agente mediador no processo de formação de um cidadão apto para atuar nessa sociedade de constantes inovações, tem como desafios incorporar as ferramentas tecnológicas no processo de ensino e aprendizagem, buscando formação continuada, bem como mecanismos de troca e parcerias quanto à utilização destas. (CANTINI et al., 2006, p. 876).

Cantini et al. (2006), entretanto, reconhecem que não se deve imputar somente ao professor a responsabilidade pela apropriação tecnológica. Certamente que a motivação é importante, mas há que se ter uma escola desejosa pela renovação e capaz de oferecer subsídios para que a ação docente seja instigante e inovadora.

Também preocupados com a questão pedagógica no contexto digital, Lewgoy e Arruda (2003) expõem que a expansão da Internet e das TDIC têm desafiado os professores a repensarem e inovarem as suas práticas pedagógicas no contexto do século XXI. Entendem que o binômio estabelecido entre tecnologias e Educação Superior tem se constituído em experiências ainda esparsas. Sinalizam, entretanto, que o indivíduo está imerso em um contexto muito mais dinâmico, interativo e proativo, muito diferente daquele em que foram estruturados os moldes educacionais anteriores à chegada da Internet.

$\mathrm{O}$ contexto digital requer um professor que não seja apenas um transmissor do conhecimento, mas também um provocador em uma sociedade que tem demandado sujeitos críticos, competentes, criativos e flexíveis. Nesse cenário, práticas pedagógicas endurecidas e enrijecidas devem ser flexibilizadas e a elas agregadas outras que coloquem os estudantes como produtores do conhecimento. O professor passa a ser o agente mediador nesse processo, conforme apontam Costa et al. (2012), Cortella (2014) e Leite et al. (2009). 
Na mesma linha de argumentação, Baladeli, Barros e Altoé (2012) entendem que tal mudança impõe novas formas de ensinar e aprender, as quais não cessarão de se transformar, pois o acesso à informação e ao conhecimento, ainda que não sejam sinônimos, tem se dado de forma até então impensada. Nesse sentido, atualização e busca contínua pelo saber passam a ser palavras de ordem nesta sociedade permeada pela informação e pelo conhecimento em que se espera da educação contribuições significativas na preparação de futuros profissionais.

Se, de um lado, a maioria dos alunos têm apresentado maior domínio das TDIC, utilizando-as de forma desbravadora, nem sempre a serviço de sua formação profissional, de outro os professores as têm utilizado de forma limitada nos processos de ensino e aprendizagem. Encará-las como um incômodo ou algo que possa vir a substituí-los é uma falsa ideia, conforme explicita Demo (2005 apud CANTINI et al., 2006, p. 879): "parece evidente a dificuldade de transformar as tecnologias em oportunidades de aprendizagem sem a mediação do professor. Qualquer artefato técnico implantado na escola só frutifica sob a mediação do professor".

$\mathrm{E}$, ainda que persistam limites em relação à apropriação e ao uso de tecnologias por parte dos professores, o desenvolvimento contínuo de tais artefatos cria um cenário no qual não se pode mais ignorar a presença e os potenciais usos das TDIC nos processos de ensino e aprendizagem. Elas devem ser vistas como recursos que podem enriquecer a aula, potencializar os processos reflexivos, contribuindo assim para a (re)elaboração de novos saberes, pois permitem hoje agregar, de forma imediata, informações antes indisponíveis, como a geoinformação de uma unidade de saúde.

Considerando-se, pois, os recursos trazidos pelas TDIC, cabe aos professores, conforme defende Almeida (2012), se apropriarem de tais recursos e colocá-los não somente como suporte para expressões da realidade cotidiana, mas também para a busca e sistematização de informações de forma compartilhada. Nesse sentido, as TDIC são artefatos que instigam a cooperação e parceria na produção do conhecimento e podem contribuir para processos educativos que superem os limites entre o físico e o virtual

O desafio que se impõe hoje aos professores é reconhecer que os novos meios de comunicação e linguagens presentes na sociedade devem fazer parte da sala de aula, não como dispositivos tecnológicos que imprimem certa modernização ao ensino, mas sim conhecer a potencialidade e a contribuição que as TDIC podem trazer ao ensino como recurso e apoio pedagógico às aulas presenciais e ambientes de aprendizagem no ensino a distância. (PEÑA [20_?] apud CANTINI et al., 2006, p. 881).

Nesse contexto, a prática interdisciplinar se torna fundamental. Segundo entendimento de Cantini et al. (2006), faz-se necessária a soma de esforços entre pedagogos, professores e profissionais da área de tecnologia. Tal parceria pode contribuir para maior efetivação no uso dos artefatos tecnológicos pelos docentes, bem como no estabelecimento de programas de formação continuada. Uma boa solução nesse sentido pode ser a criação de equipes responsáveis pela capacitação e pelo uso desses recursos nos processos de ensino e aprendizagem, pois

O professor precisa desmistificar-se e buscar utilizá-las como ferramentas facilitadoras do processo de ensino e aprendizagem e, para tanto, faz-se necessário capacitação constante por parte do corpo docente, pois por meio de um manuseio adequado das tecnologias disponíveis conseguiremos fazer com que haja uma maior interação entre professor aluno e aluno-aluno e o aprender não ficará restrito apenas às salas de aula, mas sim incorporado na realidade do próprio aluno. (CANTINI et al., 2006, p. 882). 
Acredita-se que os avanços das TDIC e sua presença nos espaços educacionais e entre os estudantes acabe por colocar à docência um repensar sobre tal exercício. Ademais, entende-se que à competência teórica que cada professor carrega consigo se faz necessário agregar novas competências, em especial as de cunho digital. Em relação à essa questão, Costa et al. (2012) classificam as competências em TDIC em três níveis, conforme o Quadro 1.

\section{Quadro 1 - Níveis de certificação das competências pedagógicas em TDIC para os professores}

\begin{tabular}{|c|c|c|}
\hline 1 Competências digitais & 2 Competências pedagógicas em TDIC & 3 Competências pedagógicas em TDIC nível avançado \\
\hline $\begin{array}{l}\text { Utiliza instrumentalmente } \\
\text { as TDIC como ferramen- } \\
\text { tas funcionais no seu con- } \\
\text { texto profissional. }\end{array}$ & $\begin{array}{l}\text { Integra as TDIC como recursos pedagógi- } \\
\text { cos, mobilizando-as para o desenvolvimen- } \\
\text { to de estratégias de ensino e de aprendiza- } \\
\text { gem, numa perspectiva de melhoria das } \\
\text { aprendizagens dos alunos. }\end{array}$ & $\begin{array}{l}\text { Inova práticas pedagógicas com as TDIC, mobilizando as } \\
\text { suas experiências e reflexões, no sentido de partilha e colabo- } \\
\text { ração com a comunidade educativa e numa perspectiva } \\
\text { investigativa. }\end{array}$ \\
\hline
\end{tabular}

Fonte: Costa et al.(2012,p. 92).

Trata-se, portanto, de agregar competências de cunho digital à solidez teórica que os professores carregam consigo, não apenas como mais uma ferramenta de apoio para um debate teórico sobre determinado tema ou a transmissão de um determinado saber, mas também como meio de fortalecer o processo de aprendizagem dos alunos.

Entende-se, portanto, que dos professores é demandada uma competência pedagógica em relação às TDIC com o objetivo de colocar toda a curiosidade e habilidade dos estudantes no manuseio de tais recursos, a favor da produção do conhecimento. Destarte, pretende-se que o mero instrumento de comunicação ou de acesso à informação seja transformado em algo para além de um uso social. Romper com os limites de utilização por parte dos estudantes implica romper, primeiro, com os limites de utilização pedagógica de tais artefatos por parte do professor.

Requer-se dos professores, portanto, o reconhecimento de que as TDIC podem ser úteis nos processos de aprendizagem, gerando, inclusive, melhor rendimento escolar. Tal reconhecimento, todavia, só se torna possível à medida que cada professor conhece o que cada tecnologia pode oferecer nos processos de ensino e aprendizagem e, dessa forma, vinculá-la aos objetivos de aprendizagem traçados. Demanda-se, portanto, um conhecimento mínimo sobre as tecnologias, o que se pode fazer com elas e o grau de dificuldade em operacionalizá-las, tanto por parte dos professores como dos alunos (COSTA et al., 2012, p. 24).

\section{Caminho metodológico}

Os resultados a seguir são fruto de uma survey realizada com assistentes sociais que ministram aulas em cursos de graduação de Serviço Social em universidades públicas no estado do Paraná. As pesquisas em que se interroga diretamente as pessoas cujo comportamento se deseja conhecer denominam-se survey ou levantamento (GIL, 1999). Trata-se de uma modalidade que possibilita conhecer as crenças e opiniões do grupo e favorece a coleta de dados em grande quantidade e de forma rápida. $\mathrm{O}$ fio condutor dessas pesquisas está na descrição das características de uma população ou de um fenômeno específico, juntamente com os estudos que se voltam a processos ligados à prática (GIL, 1999). Nesse sentido, o caminho metodológico realizado foi descrever o conhecimento e os objetivos que levam os professores a utilizar as TDIC.

Para chegar aos professores, foram identificados os cursos que oferecem graduação em Serviço Social no Paraná e, para tal, foram adotados os seguintes procedimentos: a partir do site $e$-Mec, houve levantamento de informações sobre tais graduações, com base nos critérios (1) curso de Serviço Social, (2) presencial, (3) público, (4) gratuito e (5) em atividade.

Identificadas as Instituições de Ensino Superior (IES) públicas que oferecem graduações em Serviço Social, manteve-se contato com os coordenadores dos cursos, a fim de lhes apresentar a proposta da pesquisa, bem como solicitar o apoio no repasse de informações e na sensibilização dos professores para participarem desta. Delineou-se, assim, o universo da pesquisa (RICHARDSON, 2009), o qual totalizou 113 professores, assim distribuídos: 24 da Universidade Estadual do Oeste do Paraná (UNIOESTE); 25 da Universidade Estadual de Londrina (UEL); 21 da Universidade Estadual de Ponta Grossa (UEPG); nove da Universidade Esta- 
dual do Centro Oeste (UNICENTRO); nove da Universidade Federal do Paraná (UFPR); 16 da Universidade Estadual do Paraná (UNESPAR); cinco da Universidade Estadual de Maringá (UEM) e quatro da Universidade Federal da Integração Latino Americana (UNILA).

Para Freitas, Janissek-Muniz e Moscarola (2004), a Internet tornou-se um poderoso recurso para a realização de pesquisas, inclusive nesta. Por meio de um questionário on-line, foi possível obter, em tempo real, os dados da pesquisa e ir acompanhando a evolução da coleta até o seu fechamento. A interatividade passou a ser o fio condutor dos estudos realizados com o apoio da Internet.

No caso desta pesquisa, a coleta dos dados ocorreu a partir da aplicação de um questionário eletrônico, pensado de modo a obter uma sondagem junto aos professores em relação às TDIC. Especificamente, buscou-se saber o que conhecem, como utilizam e com quais objetivos o fazem. Tanto o questionário quanto o Termo de Consentimento Livre e Esclarecido (TCLE) foram enviados para o endereço eletrônico dos participantes.

O questionário foi preparado utilizando os recursos oferecidos pelo software Lime Survey ${ }^{1}$, que permite a elaboração de questões de acordo com os interesses do pesquisador e gera automaticamente os resultados da tabulação, tanto em gráficos como em tabelas, para as questões fechadas. As questões abertas foram tratadas com o auxílio do editor de planilhas (Excel). As respostas apresentadas foram listadas, unidas por aproximação, sendo identificada a frequência com que foram citadas pelos respondentes.

Dessa forma, realizou-se uma primeira aproximação com a questão dos usos das TDIC pelos docentes de Serviço Social. Os números levantados não só forneceram pistas de como tal relação tem se dado, mas também suscitaram reflexões, pois não foram visualizados apenas como números. Entendeu-se que eles acenavam para outras leituras por parte do pesquisador, extrapolando assim a sua condição de indicador numérico.

\section{Participantes da pesquisa}

O questionário on-line ficou aberto durante o mês de setembro de 2016. Aos professores foram enviados e-mails lembrando da importância de sua participação. Do universo composto por 113 professores, 77 (68\%) participantes acessaram o questionário, sendo que nem todos o concluíram. Em relação ao sexo dos respondentes, 57 (74\%) eram do sexo feminino, sete $(9,1 \%)$ do sexo masculino e $13(16,9 \%)$ deixaram de informar esse dado.

A formação em Serviço Social, em IES de caráter público no estado do Paraná, está a cargo de oito universidades. Dessas, seis são estaduais e duas são federais (no caso a UFPR e a UNILA). Quanto à pesquisa on-line, foi possível obter a participação de professores de todas as IES públicas que oferecem graduação em Serviço Social, ficando assim distribuídos: UEL, 14; UEM, 1; UEPG, 11; UFPR, 6; Unespar, 8; Unicentro, 5; Unila, 1; Unioeste, 13; não informaram, 18.

Em relação à idade dos participantes, esses foram agrupados em diferentes faixas etárias. Tivemos 19 participantes (25\%) na faixa dos 20 aos 30 anos. Docentes com idade na faixa etária entre 40 e 50 anos corresponderam a 38 respondentes $(49,3 \%)$; na faixa etária dos 60 anos está o menor grupo, formado por 5 $(6,5 \%)$ professores. Em relação à essa questão, 15 (19,5\%) professores não a responderam.

Ao se voltar o olhar à questão do início das atividades docentes, no âmbito do Serviço Social, entre os participantes da pesquisa on-line encontram-se $8(10,4 \%)$ professores que iniciaram as suas carreiras como docentes na década de 1980; $18(23,4 \%)$ professores deram início às atividades como docentes nos anos 1990; a maioria deles, isto é, $27(35,1 \%)$ começaram as atividades em sala de aula a partir da primeira década do século XXI; sete $(9,1 \%)$ começaram a lecionar apenas na década passada; e 17 (22\%) professores que acessaram a pesquisa on-line não responderam a questão.

\section{Formação para o uso de TDIC por parte dos professores}

Dentre as questões que se buscou levantar a partir do questionário on-line, estavam aquelas que visaram identificar se os professores tiveram algum tipo de formação para o uso de diferentes tecnologias em suas atividades docentes. Dentre os participantes que acessaram o questionário on-line, 55 (71,4\%) afirmaram possuir computador e $22(29 \%)$ não responderam à questão. Quando perguntados se realizaram algum curso para o uso do equipamento, 21 (27\%) participantes afirmaram positivamente, $34(44 \%)$ negativamente e 22 (29\%) deixaram de responder à questão.

Dentre os respondentes que realizaram cursos para operar o computador, destaca-se que $20(80 \%)$ fizeram o curso básico de informática, ou seja, aprenderam a utilizar os recursos para a produção de textos, elaboração de planilhas, apresentação de trabalhos e de navegação na Internet. Outros cinco professores 
(20\%) realizaram cursos mais avançados, tais como: informática avançada, 1 (4\%); Sistemas Internos das IES ${ }^{2}, 2$ (8\%); Lime Survey, 1 (4\%); Moodle, 1 (4\%).

Constatou-se, ainda, que dentre os respondentes da pesquisa on-line, 43 professores (56\%) não realizaram nenhum curso para o uso das TDIC; 11 (14\%) afirmam ter buscado capacitação para o uso de tais recursos; e $23(30 \%)$ não responderam à questão. A questão aberta, versando sobre capacitação para o uso de TDIC, teve como respondentes apenas 13 participantes (17\%). Dentre os cursos que afirmaram ter realizado para o uso de TDIC, destacam-se: preparação para o ensino à distância, 4 (30,8\%); construção de blogs, 1 (7,7\%); sistemas internos da IES, 3 (23\%); disciplina na pós-graduação, 1 (7,7\%); elaboração de slides, 1 $(7,7 \%)$; Moodle, 1 (7,7\%); recursos do Google, $1(7,7 \%)$, software para análise de dados, $1(7,7 \%)$.

\section{Utilização das TDIC nos processos de ensino-aprendizagem}

Em relação ao uso das TDIC como recursos para os processos de ensino e aprendizagem, a pesquisa on-line apontou que $16(21 \%)$ professores dizem não as utilizar; $39(51 \%)$ professores afirmam utilizar as TDIC para o ensino; e 22 (28\%) não responderam à questão.

Dentre os recursos que foram citados pelos professores como suporte para o processo de ensino, a tríade formada por computador, projetor multimídia e editor de slides (PowerPoint), juntamente com a Internet, foram os itens mais apontados (46,4\%). Em segundo lugar (30,9\%), recursos audiovisuais (TV, caixa de som, CDs, DVDs, filmes, vídeos, videoaulas, imagens, músicas). Base de dados (revistas, sistemas de informação da instituição, sistemas de gestão das políticas sociais, sites, buscadores) correspondeu a $12,4 \%$ das citações. Blogs, redes sociais, fórum, WhatsApp, comunidades virtuais, por sua vez, tomaram 10,3\% das menções.

Em relação ao incentivo, por parte dos professores, ao uso das TDIC nos processos de aprendizagem dos estudantes, 18 (23\%) professores afirmaram que não o fazem; 36 (47\%) declararam fazer esse tipo de estímulo; e 23 (30\%) abstiveram-se de responder, tendo apenas acessado o questionário.

Ao somar os percentuais dos professores que afirmam não incentivar o uso das TDIC com aqueles que se abstiveram de responder, e partindo do princípio de que esses também não o fazem, obtém-se um total de 41 professores (53\%) que não incentivam o uso de tecnologias em suas salas de aula.

Quanto ao incentivo ao uso das TDIC pelos alunos em sala de aula, os professores afirmam que estimulam o seu uso de modo a complementar a temática da aula, o que pode ser feito a partir do acesso a bases de dados para buscar material, sejam estes de ordem textual ou de imagens. Em segundo lugar, o uso mais incentivado por parte dos professores em relação ao uso das TDIC pelos alunos está na elaboração dos trabalhos acadêmicos. O Quadro 2 permite visualizar essas informações.

\section{Quadro 2 - Como os professores incentivam o uso das TDIC pelos estudantes}

\begin{tabular}{l|c|c}
\hline Categoria & $\mathbf{N}^{\circ}$ & $\mathbf{\%}$ \\
\hline Edição de vídeos & 1 & 2 \\
\hline Incentivo à realização de cursos para uso de bancos de dados, cadastros eletrônicos & 1 & 2 \\
\hline $\begin{array}{l}\text { Indicação ou permissão de acesso a bases de dados para complementação do tema da aula (teses, } \\
\text { dissertações, revistas científicas, indicadores, vídeos, imagens) }\end{array}$ & 28 & 54 \\
\hline $\begin{array}{l}\text { Na elaboração e apresentação de trabalhos (artigos, projetos, elaboração de textos, planilhas, gráficos, } \\
\text { uso de projetor multimídia) }\end{array}$ & 12 & 23 \\
\hline Realização de aulas no laboratório de informática & 4 & 8 \\
\hline $\begin{array}{l}\text { Reflexão sobre usos, possibilidades e limites das TDIC (acesso aos usuários, às redes sociais, aos } \\
\text { serviços sociais etc.) }\end{array}$ & 6 & 12 \\
\hline Total & $\mathbf{5 2}$ & $\mathbf{1 0 0}$ \\
\hline
\end{tabular}

Fonte: Elaboração própria com base em pesquisa on-line (2016).

Por fim, e em relação às TDIC, foi solicitado aos professores que sugerissem temáticas para a formação e o uso dessas tecnologias. Dentre as sugestões apresentadas pelos respondentes da questão, se destacam 
as seguintes sugestões e temáticas: concepção e uso das TDIC (32\%); o uso de tais recursos para a pesquisa (19\%); o uso pedagógico das TDIC (14\%); e elaboração de slides (10\%).

\section{Algumas reflexões a partir do levantamento de dados}

Em relação ao perfil dos participantes, os dados mostram que o grupo é composto, em sua maioria, pelo que a literatura denomina de migrantes digitais - profissionais que nasceram antes do surgimento da Internet e do computador. Ao longo de suas vidas, foram cercados pelos avanços trazidos pelo computador, pela Internet e pelas tecnologias móveis. Diferentemente da geração nascida a partir dos anos 2000 - os nativos digitais -, para os migrantes digitais as tecnologias passaram a fazer parte de suas vidas já na fase adulta.

Acredita-se que, mesmo para os professores caracterizados como migrantes digitais, a questão das TDIC seja um tema que não lhes passou desapercebido, o que pode ser observado a partir dos dados trazidos pelo levantamento on-line. No total, 77 (68\%) participantes que compunham o universo (113) acessaram o questionário on-line, o que revela um significativo interesse pela questão.

Cabe destacar o perfil etário dos participantes. Os dados apontam que em sua grande maioria são professores na faixa etária entre 40 e 60 anos. Trata-se, portanto, de um grupo de professores formados em um período que antecedeu ao boom da Internet e ao surgimento das tecnologias móveis. O uso de tais recursos não compôs o seu processo de formação, mas vem se dando de forma paulatina e com limitações.

Ao olhar para o grupo sob a perspectiva da docência, percebe-se que se trata de professores que, em sua maioria, iniciaram suas carreiras como docentes entre a década de 1980 e o início dos anos 2000, período em que a Internet começava a se popularizar no País. Cabe lembrar que a inclusão da informática no processo de formação do assistente social só ocorreu no ano de 1996, com as Diretrizes Curriculares para os cursos de Serviço Social. E, em tese, a partir de então, tal domínio deveria se dar ao longo da graduação.

Quando se atenta para o preenchimento completo do questionário, a participação engloba 52 (46\%) participantes. A escolha por responder às perguntas decai ao longo do questionário. Dessa forma, anteriormente às questões voltadas às TDIC, havia entre 15 (19\%) e 17 (22\%) professores que acessaram o questionário, mas que não haviam respondido às questões. No momento em que se passou para a seção de perguntas relacionadas às TDIC, tal índice saltou para 23 (30\%) professores que deixaram de responder às questões.

Isso significa que, se de um lado a pesquisa despertou o interesse dos participantes pelo fato de ser um estudo sobre à docência na área do Serviço Social, de outro a temática central - TDIC - pode ter provocado um afastamento daqueles que não se sentiram à vontade em responder as questões específicas sobre o seu uso, seja por não utilizá-las ou porque as questões de algum modo levam a refletir sobre os seus limites em relação a tais recursos.

Esse silêncio em relação às questões voltadas ao uso das TDIC acaba por suscitar outras hipóteses, entre elas a de que esses professores não utilizam nenhum recurso em TDIC para os seus processos de ensino e, muito menos, as direcionam à aprendizagem. As TDIC não comporiam o repertório de recursos didáticopedagógicos utilizadas por eles.

Os dados coletados apontam, ainda, para uma atitude de abertura ao uso das tecnologias entre os respondentes. Grande parte do grupo declara possuir o computador e dele fazer uso; todavia, a maior parte não realizou nenhum tipo de curso para utilizá-lo. Depreende-se daí que foram aprendendo à medida que o utilizavam em suas atividades e ativeram-se ao domínio de recursos básicos em informática, como editores de textos, de planilhas e apresentações.

Perguntados se costumam incentivar os estudantes a usarem as TDIC em sala de aula, alguns professores afirmaram que sim; entretanto, as respostas apontam que, dentre os recursos estimulados, estão aqueles com os quais os professores trabalham e que são dominados por eles (editores de textos, planilhas e apresentações), principalmente para a elaboração dos trabalhos acadêmicos. Nesse sentido, não se avançou no uso ou incentivo de possiblidades de trabalho com as bases de dados sociais e econômicas, como as do Instituto Brasileiro de Geografia e Estatística (IBGE), do Instituto Paranaense de Desenvolvimento (Ipardes) ou do Sistema Único de Saúde (Sus), o DataSus, entre outros.

Nenhum dos respondentes afirmou utilizar as TDIC no ensino sobre a prática profissional do assistente social - como na elaboração de bancos de dados para registro diário das intervenções realizadas, no acesso aos usuários dos serviços sociais, na questão da interação entre profissional e usuários em redes sociais, na gestão da informação e na produção do conhecimento sobre a realidade social com o auxílio de TDIC - tais como o Google Earth ${ }^{3}$, o gvSIG $^{4}$, ou pesquisas de sondagem utilizando o Google Docs, ou outros softwares para pesquisa de opinião.

Se considerada a gama de recursos existentes atualmente para a elaboração de dados, produção de informações e conhecimento - elementos essenciais para o exercício profissional do assistente social -, perce- 
be-se que tais recursos estão sendo subutilizados para tal finalidade. Essa situação indica que estão sendo formados profissionais que perpetuarão o ciclo vicioso, pelo qual o professor não explora, o aluno deixa de conhecer e saber as possibilidades existentes em relação às TDIC, e o futuro profissional não reconhece a potencialidade de tais recursos para as suas atividades cotidianas.

Conforme os dados levantados pela pesquisa, as TDIC têm sido utilizadas para o ensino e, nesse sentido, se limitado à tríade formada por computador, projetor multimídia e editor de slides (PowerPoint), ancoradas na Internet. A não apropriação (e o não uso) de outros recursos em tecnologias para além desse tripé leva a crer que tais ferramentas têm sido utilizadas para a exposição de conteúdo em sala de aula ou para o reforço daquilo que já foi exposto. Depreende-se que a utilização de tais recursos tem se dado de forma a modernizar o processo de ensino e, segundo definição de Costa et al. (2012), como tecnologia do professor e não como algo a ser apropriado de forma ativa pelos estudantes.

Os recursos utilizados pelos respondentes em relação às TDIC apontam, portanto, para a sua apropriação e uso como mais um meio para o exercício do ensino. Da mesma forma como o quadro, o livro, o texto, o giz ou o pincel, também o computador, o projetor multimídia e os slides têm sido utilizados na transmissão do conhecimento por parte do docente. Entende-se, assim, que há a perpetuação de um modelo historicamente posto, em que o professor ensina e o aluno absorve, isto é, para além do recurso, há um entendimento do que seja a prática pedagógica se sobrepondo às TDIC.

\section{Considerações finais}

O índice de participação de mais de 50\% do universo de professores aponta para a relevância da pesquisa, pois sinaliza a existência de interesse pela temática por parte da categoria de profissionais pesquisados. Denota, ainda, que a questão das TDIC entre a categoria pesquisada se coloca como algo latente, ou seja, é um tema que parece percorrer o universo de preocupações desses profissionais. Trata-se, portanto, de um assunto que pode vir a ser explorado em estudos futuros.

Se a adesão e o uso das TDIC nos espaços da formação se mantiverem nos limites encontrados se deixará de estimular futuros profissionais a explorarem essas tecnologias como recursos em suas atividades.

Tal situação pode acabar por reverberar no espaço de trabalho do futuro assistente social. Em consequência, serão formados profissionais que, mesmo dispondo de bancos de dados e sistemas de informação e gerenciamento de políticas sociais, tais como o SuasWeb, Sipia e DataSus, para citar os mais atinentes ao exercício profissional, acabarão por não saber otimizar tais recursos, tampouco os dados e as informações disponíveis em tais sistemas.

A oferta de recursos atualmente existentes em TDIC permite a elaboração, a circulação, a partilha de dados e informações, bem como a produção de conhecimento sobre determinada área. Neste vasto e crescente cenário digital, se faz necessário investir na alfabetização digital ou, se assim puder ser denominada, competência digital, entendida como o uso crítico das TDIC. Segundo Arrieta e Montes (2011), alfabetização digital implica criatividade, pensamento crítico e de avaliação, compreensão social e cultural, colaboração, habilidade para encontrar e selecionar informação, comunicação efetiva e segurança em Internet. As TDIC passam a ser hoje uma forma de chamar os estudantes à participação no processo de ensino e aprendizagem. Ou seja, saber que não se está falando de um recurso neutro, mas que pode ser direcionado de forma estratégica a serviço do monitoramento e da garantia de direitos sociais. Significa, portanto, ir além do domínio e da competência instrumental das TDIC.

Cabe, portanto, acrescer à perspectiva teórico-hegemônica da profissão o olhar crítico de Feenberg (2013). Para o autor, não se perdem de vista os interesses que perpassam o desenvolvimento tecnológico e a cesta de valores que cercam tal empreitada, mas é possível acrescer outros valores que não aqueles que a sobrecarregam. Sob esta perspectiva, as TDIC podem, pois, vir a contribuir significativamente com a formação e o exercício profissional no âmbito do Serviço Social.

\section{Referências}

ALMEIDA, M. E. B. Prefácio. In: COSTA, F. A. et al. (org.). Repensar as TDIC na educação: o professor como agente transformador. Carnaxide: Santillna, 2012.

ARRIETA, C. A.; MONTES, V. D. Alfabetización digital: uso de las TIC's más allá de una formación instrumental y una buena infraestructura. Revista Colombiana de Ciência Animal, v. 3, n. 1, 2011. Disponível em: https://www.medigraphic.com/cgi-bin/new/ resumen.cgi?IDARTICULO=44800. Acesso em: 17 jan. 2015. 
BALADELI, A. P. D.; BARROS, M. S. F.; ALTOÉ, A. Desafios para o professor na sociedade da informação. Educar em Revista, Curitiba, n. 45, p. 155-165, set. 2012. Disponível em: http://www.scielo.br/scielo.php?script=sci_arttext\&pid=S0104$40602012000300011 \& \operatorname{lng}=$ en\&nrm=iso. Acesso em: 22 maio 2017.

CANTINI, M. C. et al. O desafio do professor frente às novas tecnologias. In: CONGRESSO DE EDUCAÇÃO DA PUCPR, 6., 2006, Curitiba. Anais [...]. Curitiba: Champagnat, 2006. p. 875-883. Disponível em: http://www.pucpr.br/eventos/educere/educere2006/ anaisEvento/docs/CI-081-TC.pdf. Acesso em: 18 jun. 2016.

CORTELLA, M. S. Educação, escola e docência: novos tempos, novas atitudes. São Paulo: Cortez, 2014.

COSTA, F. A. et al. (org.). Repensar as TDIC na educação: o professor como agente transformador. Santillana: Carnaxide, 2012.

FEENBERG, A. O que é filosofia da tecnologia? In: NEDER, R. T. (org.). A teoria crítica de Andrew Feenberg: racionalização democrática, poder e tecnologia. 2. ed. Brasília: Observatório do Movimento pela Tecnologia Social na América Latina/CDS/UnB/Capes, 2013. p. 51-64.

FREITAS, H.; JANISSEK-MUNIZ, R.; MOSCAROLA, J. Dinâmica do processo de coleta e análise de dados via web. In: CONFERÊNCIA INTERNACIONAL DO BRASIL DE PESQUISA QUALITATIVA (CIBRAPEQ), 1., 2004, Taubaté. Anais [...]. Taubaté, 2004. 12 p. Disponível em: http://gianti.ea.ufrgs.br/files/artigos/2004/2004_157_CIBRAPEQ.pdf. Acesso em: 5 fev. 2019. GIL, A. C. Métodos e técnicas de pesquisa social. 5. ed. São Paulo: Atlas, 1999.

LEITE, L. S. et al. (org.). Tecnologia educacional: descubra suas possibilidades na sala de aula. 3. ed. Petrópolis: Vozes, 2009. LEWGOY, A. M. B; ARRUDA, M. P. Da escrita linear à escrita digital: atravessamentos profissionais. Textos e Contextos, Rio Grande do Sul, v. 2, n. 2, p. 1-10, dez. 2003. Disponível em: https://www.researchgate.net/publication/267377598_09_Da_Escrita_ Linear_A_Escrita_Digital_Atravessamentos_Profissionais. Acesso em: 9 out. 2016.

RICHARDSON, R. J. Pesquisa social: métodos e técnicas. 3. ed. São Paulo: Atlas, 2009.

WIKIPÉDIA. Google Earth. Disponível em: https://pt.wikipedia.org/wiki/Google_Earth. Acesso em: 26 jan. 2020.

WIKIPEDIA. GvSIG. Disponível em: https://pt.wikipedia.org/wiki/GvSIG. Acesso em: 26 jan. 2020.

\section{Notas}

1 O Lime Survey é um software utilizado para pesquisas on-line, da mais simples às mais complexas. Cf.:https://www.limesurvey.org/pt/.

2 Sistemas para o registro de notas e outras demandas acadêmicas.

3 Google Earthé um programa de computador desenvolvidoe distribuído pela empresa estadunidense Google, cuja funçãoé apresentar um modelito tridimensional do globo terrestre, construído a partir de mosaico de imagens de satélite obtidas de fontes diversas, imagens aéreas e GIS 3D. (Cf.: https://pt.wikipedia.org/wiki/Google_Earth).

4 GvSIGé um software livre de SIG de fonte aberta desenvolvido pela Conselleria d'Infraestructures i Transports da Comunidade de Valência, com o apoio da União Europeia. O GVSIG é distribuído sob a licença GNU GPL. (Cf.: https://pt.wikipedia.org/wiki/GvSIG).

\section{Antonio Sandro Schuartz}

antoniosersocial@gmail.com

Doutor em Serviço Social pela Universidade Federal de Santa Catarina (UFSC)

Professor da Universidade Federal do Paraná (UFSC)

\section{UFPR}

Rua Jaguariaíva, 512

Matinhos - Paraná - Brasil

CEP: 83.260-000

\section{Hélder Boska de Moraes Sarmento}

hboska@yahoo.com.br

Doutorado em Serviço Social pela Pontifícia Universidade Católica de São Paulo (PUC/SP)

Professor da Universidade Federal de Santa Catarina (UFSC)

\section{UFSC}

Campus Universitário Reitor João David Ferreira Lima - Trindade

Florianópolis, SC, Brasil

CEP: 88040-900 


\section{Agradecimentos}

Sinceros agradecimentos aos docentes, sujeitos desta pesquisa, que se disponibilizaram a contribuir com a construção de conhecimentos. No mesmo sentido, registro o meu reconhecimento aos colegas do colegiado do curso de Serviço Social da UFPR por terem assumido os meus encargos didáticos, possibilitando assim minha saída para cursar o Doutorado.

\section{Agência financiadora}

Não se aplica.

\section{Contribuições dos autores}

Artigo fruto de pesquisa para doutoramento realizada pelo Prof. Dr. Antonio Sandro Schuartz, sob orientação de Hélder Boska de
Moraes Sarmento. A pesquisa survey foi realizada pelo doutorando, com acompanhamento e orientação, sendo a sistematização deste artigo realizada com a colaboração entre os dois pesquisadores.

Aprovação por Comitê de Ética e consentimento para participação

Não se aplica.

\section{Consentimento para publicação}

Consentimento dos autores.

\section{Conflito de interesses}

Não há conflito de interesses. 